\title{
The Influence of Global Internet Governance Institutions on the EU
}

\author{
George Christou (Politics and International Studies, University of Warwick) \\ Seamus Simpson (Information and Communications, Manchester Metropolitan \\ University)
}

\section{DRAFT}

Paper presented to the workshop 'The Influence of International Institutions on the EU’, Institut Barcelona d'Estudis Internacionals, Barcelona, 6-7 May, 2010. 


\begin{abstract}
Since the mid-1990s, the EU has sought to engage in the formation and development of the most important multilateral Internet governance institutions, and, in doing so, has portrayed itself as a leading and influential player in the evolving global Internet governance process. The EU has, albeit with varying degrees of success, projected a normative model for Internet governance reflective of its own domestic preferences. A topic as yet very much under-addressed in the literature, however, is the extent to which the EU has absorbed and diffused internally norms and practices from emerging global Internet governance institutions. This paper makes a contribution to establishing how far the EU's engagement with global Internet institutions has contributed to the evolution of its own 'internal' governance of the Internet. The conditions under which this has occurred, the key actors involved and the associated policy outcomes are core topics which this paper addresses. Focusing on two characteristically different bodies, the Internet Corporation for Assigned Names and Numbers (ICANN) and the Internet Governance Forum (IGF), the chapter shows how through its presence in these fora, the EU has engaged with three core practices of Internet governance articulated globally: private interest regulation, multi-stakeholderism, and self-regulation.
\end{abstract}




\section{INTRODUCTION}

The Internet is an increasingly important aspect of global social, political and economic life. The international strategic significance of the Internet has led to a number of efforts aimed at coordinating, at the global level, the complex and burgeoning series of policy issues at the heart of its functioning. Here, a range of business, civil society, governmental and technical interests have converged around the creation and subsequent functioning of a relatively new set of institutional contexts. These institutions have, for global bodies, often operated according to relatively novel norms and practices.

The European Union (EU) has attempted to play a prominent role in the evolution of global Internet governance at the institutional level. The global character of the Internet marked it out at an early stage as an instance of policy territory within which the EU, through the European Commission, might exercise its representational role on behalf of Member States. There is some evidence to date in the literature of the attempts made by the EU to articulate a policy on Internet governance and to promote this within key global institutional contexts (see Christou and Simpson 2007; Leib 2002), where the conclusion has tended to be that it has only achieved incremental rather than transformational success in respect of its objectives. However, a significant gap in the literature exists in terms of the influence which the EU's, albeit relatively short, engagement with global Internet governance institutions has had on the development of its own policies for governing the Internet.

Drawing on a number of core themes of the volume, this chapter aims to provide a contribution to closing this gap. First, the chapter considers the extent to which the EU has acted as an amplifier or, by contrast, a filterer and re-interpreter of global Internet governance practices. Second and related, the chapter illustrates how, on the one hand, new global Internet institutional contexts have provided the EU with access to deliberative and decision processes that would otherwise have been out of its reach. However, on the other, at least to some extent, this exposure has led to the EU being influenced by the contexts with which it has engaged. Third, the chapter makes an assessment of the degree of impact (Radaelli 2002) on the EU as a result of its engagement with global Internet institutional contexts. Here, there is some evidence of absorption and transformational impact, the latter where a new EU-wide policy 
network has emerged in which the EU holds a relatively powerful position and, beyond that, the EU's competence in the field of Internet governance issues has increased. An important finding of the chapter is that whilst at the outset the EU was in a relatively weak, even 'outsider', position in global Internet governance and thus might be expected to be a 'policy taker', as time has evolved its position has strengthened. Thus, degree of impact is in part a function of the extent to which the EU is able to establish and exert its own preferences.

The empirical focus of the chapter is two high profile, though rather different, global Internet governance bodies: the Internet Corporation for Assigned Names and Numbers (ICANN) and the Internet Governance Forum (IGF). The chapter explores the extent to which, through its presence in these fora, the EU has engaged with three core practices of Internet governance articulated globally: private interest regulation, multi-stakeholderism, and self-regulation. The next section provides a brief context on the involvement of the EU in the early evolution of Internet governance. Beyond this, the chapter explores the issue of the practices of private interest governance and selfregulation through a brief analysis of the dot eu country code Top Level Domain which involved considerable engagement with ICANN. Thereafter, the chapter turns its attention to the IGF and in particular the practice of multi-stakeholderism in Internet governance and the extent to which the EU has engaged with, and absorbed, this novel form of governance. The final section of the chapter draws some conclusions on the influence which global Internet institutional contexts and practices have exercised on the EU over the last 10-15 years.

\section{THE EU AND THE EVOLUTION OF GLOBAL INTERNET GOVERNANCE}

Whilst now a communications environment which is increasingly global in character and function, the Internet's origins lay firmly in US socio-economic traditions and has been fundamentally shaped by them. Though funded originally through the US public purse, the non-military aspect of Internet communication developed in academic and civil society circles which dominated its original usership. The technical protocols on which the Internet's computer-to-computer communicative activities were based lay outside both broadcasting and telecommunications and, thus, technically and organisationally, the Internet developed beyond the mainstream. Its culture of communication was liberal and communitarian in nature and any perceived 
encroachment from state and commercial actors was viewed with equal scepticism (see Mueller 2002). However, through the early 1990s, a series of technical innovations which increased the Internet's user-friendliness highlighted, at the same time, its huge economic and social potential as a communications environment, thus heightening its profile as an asset of strategic economic and political significance. Thus began the Internet's popularisation and commercialisation internationally, a process which, though unleashing its huge potential, also created a series of international governance problems that the Internet's historical US-based ad hoc organisational development was incapable of dealing with. High on the list here was the need to create an institutional environment for managing access to, and presence on, the Internet, or, more prosaically, the Internet's name and address system. Through the mid-1990s, a series of negotiations between key technical, commercial and governmental parties at the forefront of Internet communication led to the creation of ICANN as a solution. ICANN has proven since to be a controversial and much contested body.

The EU had, through the 1980s and 1990s, begun to become an increasingly important locus for electronic network communications policy. Though firmly rooted historically in national contexts, the EU began to be viewed by its Member States as a useful mechanism for developing new policies in telecommunications, in particular, but also in broadcasting to some extent. A process of marketisation and a complementary system of public interest regulation began to take shape across the EU in telecommunication, replacing the traditional function of the state as system owner and operator. Importantly, this liberal market agenda was internationally expansionist in character and originated in the US (Dyson and Humphreys 1986). Within Europe, the legislative framework for it was developed at EU level and practised nationally, leading after a series of policy developments, in 2002, to the creation of the Electronic Communications Regulatory Framework (Goodman 2006). This allowed the EU to play a key role not only in the creation, but also in the implementation, of telecommunications policy agendas in conjunction with its Member States (Humphreys and Simpson 2005).

In broadcasting, the EU has also become an increasingly significant actor in policy and legislative developments (see Humphreys 2008). Like in telecommunications, 
trends in the direction of international marketisation led to EU efforts to prescribe the legislative parameters of a Single European Market in television (European Council of Minsters 1989; 1997) and, later, audiovisual media services (European Parliament and Council 2007) as well as making several important decisions on large merger activity among media companies in Europe (see Harcourt 2005). Beyond this, the EU also laid down some general prescriptions for public service broadcasting systems (Treaty of Amsterdam 1997), the provision of state aid to broadcasters (see Donders and Pauwels 2008) and, less successfully, media pluralism (Doyle 2002).

Despite this burgeoning policy activism and in distinct contrast, by the mid-1990s, the EU had barely begun to consider the importance of the Internet, which was given only a fleeting mention in its 1994 Bangemann Report, Europe and the Global Information Society. Leib (2002) argues that the EU's vision for advanced electronic communication, Integrated Broadband Communications, was premised on telecommunications-specific technical protocols and policy expectations, rather than those of the emerging Internet. However, as the 1990s progressed, the EU became increasingly aware of the strategic importance of the Internet and, thus, the need to gain as much of a stake as possible in its future evolution. A relative lack of knowledge of the Internet aside, the EU was assisted by the fact that in tandem with its rise to prominence as a political actor in electronic communications within Europe, it had also begun to develop some experience of representing its Member States in global electronic communications policy-making fora. In particular, in telecommunications and audiovisual policy global trade negotiating contexts, the European Commission began to play an increasingly important role. This experience undoubtedly assisted it in taking a hand in the negotiations which eventually led to the creation of ICANN in 1998. However, the latter process was inevitably dominated by US political, technical and economic interests which played the determinative roles in shaping the initial structure and character of ICANN. Here self-regulatory, not-forprofit, private interest governance dominated, public oversight being relegated to an advisory only capacity in the Governmental Advisory Committee (GAC). Such an arrangement was one with which the EU was initially neither familiar nor comfortable (Christou and Simpson, 2007). The EU was not alone in contesting the nature and modus operandi of ICANN. In particular, smouldering dissatisfaction at the unilateral control exercised over ICANN by the US government through a contractual 
relationship between the former and the US Department of Commerce was given widespread forceful expression at the 2003 and 2005 World Summit on the Information Society (WSIS). As a result of negotiations between the two phases of WSIS, a decision was taken to create a new global multilateral forum on Internet governance matters, the Internet Governance Forum (IGF). The IGF is unique at the global level in that it is multi-stakeholder and deliberative only, a form of governance certainly beyond the kinds practised by the EU and its Member States since the inception of the former. An equally significant outcome from this period was the maintenance of US unilateral control over the Internet given renewed expression in the Joint Project Agreement (JPA), though recently loosened by the Obama administration.

Situations such as this inevitably call forth a consideration of the capacity of the EU to exert its interests in such relatively challenging environments. However, equally important, and the subject of this chapter, is the extent to which the EU is influenced by the agenda of global institutional bodies like ICANN and the IGF. Before and around the time of the Internet's rise to strategic prominence, there was considerable evidence, elsewhere in electronic communications, of the kind of possible general indicators of global institutional influence on the EU noted in the introduction to this volume. First, developments in telecommunications, in particular, suggested that the EU had the capacity to act as an amplifier of new policy agendas developed outside its boundaries. Here, proponents of the global neo-liberal transformation of the sector, particularly from the quarters of multinational corporate business, found an enthusiastic party in the shape of the European Commission. There is strong evidence that in its policy statements and proposals throughout the late 1980s and beyond, the European Commission readily extolled to its Member States, many of whom were at the time sceptical, the benefits of liberalisation and domestic and international marketisation in telecommunications (Simpson and Wilkinson 2002).

Second, however, by the time the Internet had become a vital issue of global governance, there was also important evidence of how the EU was able to act as a shield or a filter for global communications policy agendas. In telecommunications, whilst the EU accepted with alacrity the key tenets and practices of neo-liberal marketisation, at the same time it firmly ensconced universal or public service 
provision in its Electronic Communications Regulatory Framework (and its predecessors) as a counterweight. In fact, its reading and adaptation of telecommunications neo-liberalism was eventually successfully uploaded to the global institutional level in the World Trade Organization. In the audiovisual sector, the EU showed its ability to resist those elements of the international commercialisation agenda which were deemed not to be in its interests. Despite adopting liberal commercial policies as noted above, the EU also resisted a global trade agreement on the audiovisual sector in the WTO through citing the so-called 'cultural exception' (see Puppis 2008).

Third, in its policy engagement in the audiovisual and telecommunications aspects of electronic communications, there was significant evidence of the role of the EU as a policy opportunist. This undoubtedly gave the EU, and the European Commission in particular, access to institutional contexts and processes otherwise beyond its reach. It also increased the potential of the EU to influence, at least in a coordinative capacity if not a lead role, the development of communications policy agendas - and thus change - 'internally'. The rise to prominence of ideas of internationalisation and market-making in both broadcasting and telecommunications provide evidence of the European Commission developing its profile as a key representative of its Member States. This expansionist agenda as a 'purposeful opportunist' led not just to the European Commission to be keen to put forward the EU's position in global Internet fora but also created a channel through which the EU could be influenced by the character and policy activities of the global Internet governance bodies with which it engaged.

\section{ICANN AND THE DOT EU TOP LEVEL DOMAIN}

As noted above, the creation of ICANN in 1998 was a crucial landmark in the global institutionalisation of Internet governance practices. ICANN emerged from an often fractious process of debate and negotiation which had evolved through the middle part of the 1990s conducted among a range of governmental, commercial, ICT technical and civil society interests (Mueller 2002). The aim was to create a workable governance system at the global level to manage the burgeoning array of issues around the management of the Internet's naming and addressing system. Most of this work was technological and organisational in nature. However, Internet names and 
addresses, because they afford access to key communications facilities, are also underpinned by social and commercial-legal property rights - key public policy issues, in other words. The dominance of US interests in the process leading to the creation of ICANN influenced its structural features. At its inception, ICANN was underpinned by the key features of private interest governance and self-regulation. There were two important caveats to this: its contractual relationship with the US Department of Commerce and its Governmental Advisory Committee (GAC). However, both these, theoretically at least, were intended to develop arm's length relationships with the Corporation. The EU's engagement with ICANN developed from this starting point, where, as noted above, it was in a relatively unfamiliar and uncomfortable position.

It is important to note that the impact and influence of ICANN on the EU has been, in part, a function of the attempt by the latter to establish itself and exert more firmly its preferred positions on Internet governance. This is clearly illustrated in the case of the creation of the dot eu Internet Top Level Domain. The case provides an interesting example of the EU's relatively early engagement with the ICANN institutional context and its core practices of private interest governance and self-regulation. First, ICANN, and the specific matter of the dot eu TLD, provided the EU (the European Commission specifically) with an important foothold of justification for its presence in the GAC of this new global Internet governance body. The experimental nature of the evolution of Internet governance created uncertainty for the EU and its Member States. Whilst it had grown in stature as an actor in other parts of electronic network communication, it had not been firmly established, by the mid to late 1990s, that the EU would develop into the representative of its Member States in global Internet governance contexts. Whilst the EU, through the European Commission, had played a role in securing some degree of non-US governmental influence in ICANN through arguing for the creation of the GAC, the latter contained separate representation from a number of EU Member States as well as the European Commission. Second, having been granted membership of the GAC, the EU needed to cement a rationale for its presence in a global governance body like ICANN at an uncertain and contested time in its development. Dot eu provided an important access point and practical justification for the European Commission's presence in the business of ICANN, through what was, essentially, a 'governmental' forum. The latter, broadly speaking, 
concerned the allocation and management of Internet's address system. Internet Top Level Domains, manifest as the last mnemonic string in a typical Internet address or URL, were either based on nationality (country code TLDs e.g. .uk, .fr, .it) or general function (generic TLDs e.g. .com, .net, .org). In the techno-functionally dominated world of early Internet governance, the establishment of the dot eu TLD would mean that the EU had its own TLD to bring to the table. Overall, whilst it is not the case that, without dot eu, ICANN would have been an institutional body out of the reach of the EU, dot eu did provide a key issue area to help the EU establish its presence in ICANN at an early stage. In its own internal context, it also provided the EU with a means to attempt to galvanise European interests around an EU-based Top Level Domain theme in the global Internet governance landscape.

The dot eu TLD also provides a clear example of how the EU acted as an amplifier, on the one hand, but also as a filterer and re-interpreter, on the other, of ICANN's agenda of private interest governance and self-regulation. The key driver in the dot eu initiative was the European Commission. In the late 1990s, the Commission sought to raise the profile of Internet naming and addressing and specifically the merits of developing an EU TLD. Here, the practical advantages to business interests of creating an EU-framed cyber-identity were extolled. The Commission contended that the Single European Market should develop into the electronic realm and that dot eu would provide businesses with an important opportunity to develop their European identity in the electronic commercial realm (European Parliament and Council of Ministers 2002). Astutely, the Commission engaged closely at the time with ICT business and technical interests in Europe. The European Community Panel of Participants in Internet Organisation and Management (EC-POP) emerged as an important ally of the Commission's in its bid to secure the dot eu policy initiative domestically and, very importantly, globally in the ICANN context. In its efforts to determine support for dot eu, the Commission used a favoured tactic employed in electronic communications of launching a consultation. This not only helped the EU's interests - since the largely favourable responses were a platform on which its subsequent legislative proposals were based - but also simultaneously represented a further amplification throughout the EU of the importance of Internet names and addresses. 
Beyond this, however, through the dot eu policy initiative the EU also proved that it was far from simply an amplifier and wholesale adopter of ICANN's agenda for TLD governance. The dot eu case illustrates how the EU was able to re-interpret, importantly within limits acceptable to ICANN (and the broader Internet community), the latter's modus-operandi of private interest governance and self-regulation in the system of governance created for dot eu at EU level.

In very practical terms, it was necessary for ICANN's agreement to the establishment of dot eu to be secured. Initial cautiousness in ICANN about the motivation of the EU was allayed by the strong support given to the initiative by Internet technical and commercial interests in EC-POP, in essence counterparts of those interests in control of the self-regulatory 'day-to-day' business of ICANN. Equally important, though the EU is neither straightforwardly a country nor a generic entity and its TLD could not fit neatly into either the ccTLD or gTLD system as a consequence, it was agreed that an extended view of the ccTLD system could be taken to incorporate what would essentially be an international-regional TLD into the ccTLD system. This was assisted by the availability of the reserved 'eu' label held by the International Standards Organisation for purposes of this kind (authors' interview 2004). Finally, and by contrast, it soon became clear that whilst the EU wished to filter and re-interpret ICANN's system for TLD governance to a significant extent, it was also apparent that it valued and wished to adopt the core practices of private interest governance and self-regulation, albeit 'EU-ised' to its political tastes. Consequently, securing the agreement of ICANN to add dot eu to its TLD system proved relatively easy.

For the EU, negotiating and incorporating the above complexity was as necessary as it was desirable. A brief debate on whether the initiative to create dot eu might be undertaken through a quickly launched technical project was concluded by the assertion that there were core public policy issues which would require the development of relatively protracted EU legislation on the matter (European Commission Working Paper 2000). As a consequence, the governance of dot eu was imbued strongly with the state shadowed public policy characteristics of much of EU electronic communications policy, rather different from the modus operandi of ICANN at the time. A Regulation establishing dot eu was agreed by EU Member States in 2002 (European Parliament and Council 2002) and, thereafter, a set of public 
policy rules for the governance of dot eu were published (European Commission 2004) the enforcement responsibility for which lies with the European Commission. However, whilst public interest state shadowing is a key feature of dot eu, the system operates according to private interest practices, thus mirroring ICANN to a strong degree.

The centre piece of this system is the European Registry for Internet Domains (Eurid) which was chosen to run dot eu in 2003. Eurid undertakes the key management functions in respect of dot eu and, like ICANN, is a private body, run on a not-forprofit basis. It has become the central node in a new public-private transnational European governance network also incorporating the European Commission (the key public actor), a series of private, competitive domain name registrar companies and alternative dispute resolution providers (Christou and Simpson 2008). In this respect, dot eu provides a relatively low profile, though nonetheless useful, example of the transformative effects which even new global governance bodies such as ICANN can have on the EU (see Radaelli 2002). Whilst trans-European network governance has been mooted for some time in the European public policy literature (see Majone 2000), its incidence in the more likely to be observed (and internally generated) pure public form has been found to be rare in practice (Borzel 2010). A public-private transnational regulatory network like dot eu (influenced strongly by external global institutional forces) is possibly a unique example.

It is interesting to note that in the formation period for dot eu the European Commission's relationship as PPR enforcer stood in contrast to the GAC's advisory only relationship with ICANN. However, since around 2002, it has been argued that, de facto, the GAC's advice to ICANN has been followed in a more or less obligatory fashion (Mueller 2008). This is a clear illustration of inevitable development of the institutional agenda of new global governance bodies such as ICANN and one which the EU was notable in arguing to take place (see Christou and Simpson 2007). Thus, whilst the case of dot eu illustrates strongly the influence which a global body has had on the EU, it is also an example of how inter-institutional relationships of this kind can be dialectical in nature. It is an interesting feature of the impact that global bodies have on institutions like the EU, that real impact is unlikely to be achieved without a degree of accommodation (and perhaps some degree of absorption) of EU interests. 


\section{THE INTERNET GOVERNANCE FORUM (IGF)}

There is no doubt that the IGF, established in 2005 at the second phase of the World Summit on the Information Society process as a multilateral, multi-stakeholder, democratic and transparent institutional forum for discussing issues of Internet governance, has impacted on the EU in terms of both policies and, perhaps more significantly, on principles of governance. The EU was 'very supportive of the IGF from the beginning...' and saw it as a 'unique frame...open to everyone to discuss all tropics' (authors' interview 2009). The IGF, in EU terms, was seen as the most effective way forward given the alternative, which was to involve governments in the day-to-day business of the Internet: such an option was seen as negative, non-dynamic and a constraint on the evolution of the Internet technically, socially, politically and economically. In this context, the multi-stakeholder model was seen as the most dynamic for the EU in moving the Internet forward and finding solutions to policy and governance issues (authors’ interview 2010).

In theoretical terms, it can be argued that the institutional form of the IGF and the normative principles that underpin it, have ensured that it has gained support from many international actors, including those within the EU that are involved in formulating policy on Internet governance and acting in the day-to-day business of global Internet fora. What is even more salient with the IGF is the extent to which its institutional form has been 'mimicked' within the EU (and broader European and global space). Thus, the impact of the IGF has been multilayered and multilevel, rather than focused narrowly within the EU or on key EU institutional actors and entrepreneurs. In addition, the nature of the IGF has meant that its impact has been more normative than coercive. The IGF mandate at the WSIS Summit in Tunis (2005) stipulated that it 'would have no oversight function and would not replace existing arrangements, mechanisms, institutions, or organisations, but would involve them and take advantage of their expertise. It would be constituted as a neutral, non-duplicative and non-binding process' (WSIS, Tunis Agenda for the Information Society, 2005). Importantly the IGF was constituted as a body that would not make decisions - rather, it would arrive at positions through deliberation, where discussions were open, free and frank on any themes seen as important for the future of Internet governance (for example, child protection, security, governance). Its normative strength has been in its inclusive and bottom-up nature, and in the fact that in its first five years, in the words 
of one EU official active in Internet governance and the IGF, it has become a 'forum for learning through discussion of ideas - that you can take back and include in policy...[it] provides some new ideas to approach issues' (authors' interview, 2009).

Thus, the IGF is an institutional body that is based on non-hierarchical relations, and dense interaction through informal, networking, that has provided for a environment where information can be shared among Internet governance actors and where nonbinding propositions constructed within its deliberative fora (workshops) have been utilised to enhance EU policy. Research evidence is sparse on the concrete impact of the IGF on EU policy (and more generally on Internet governance policy globally and at local and national levels) given its short lifespan, the nature of the institution, and the fact that there is no clear diffusion process given its make-up. However, the EU, and the European Commission in particular, has used the IGF as a forum for benchmarking the evolution of its own policy in certain Internet governance issueareas and incorporating aspects of policy discussed within the IGF in order to innovate and improve EU policy. One such policy area is the EU's approach to rolling out IPV6 technology (Internet address numbering policy). According to one official, 'the Commission has set out an Action Plan in this area. What they use the IGF more for is benchmarking. Where is the EU compared to the US, China and the developing world?...because there are some countries like Malaysia...that are quite well advanced....and the EU will explore how they have got so far, so quickly...so in that respect I think the EU will use the IGF for some informal benchmarking... and to say to Member States you should be looking to do X or Y...' (authors' interview 2010).

In terms of institutional 'mimicry' and the principles of the IGF, it is clear that multistakeholderism as a norm for governing the Internet has been supported and 'absorbed' by the EU and its Member States in several ways. In the context of the current ongoing review of the IGF, those actors representing the EU within the (UN) review process have espoused the view that the 'European Union maintains its conviction of the usefulness of this Forum as a non-binding multi-stakeholder platform and the need for its continuation for at least the next five years' (Delegation of the UN, letter to Ban Ki-moon, 26 March 2010). Moreover, the EU has demonstrated its commitment to the principle of multi-stakeholderism in several ways. First, and normatively, the EU has expressed support for the extension of the 
IGF for another five years 'in order to maintain well-established best practices developed in the context of the IGF that reflect this principle' (ibid). Second, and given the success of the institutional practices at the IGF, the European Parliament in its resolution on the second Internet Governance forum (Rio de Janeiro, Nov 2007) called for the construction of a European IGF, and in this sense, has been a one of the most active EU actors promoting the creation of the IGF's institutional form in Europe. In its call it stated that 'the European Union's responsibility is to support this process, as it gives a positive and concrete context to the shaping of the Internet's future on the basis of a multi-stakeholder approach' and went on to stress 'that lessons can already be learnt from the fruitful exchanges held in the context of the IGF up to now, and put in motion, notably on electronic communications regulatory aspects and data security and privacy issues...' (European Parliament, 2008). Furthermore, the European Parliament was very supportive (along with the Council of Europe) of establishing the European Dialogue on Internet Governance (EuroDIG) with a similar working format to the IGF. EuroDIG is an open platform for informal and inclusive discussion and exchange on public policy issues related to Internet Governance (IG) between stakeholders from all over Europe. Indeed, the EP, the EU Presidency, and the European Commission have all been active within this forum alongside other European stakeholders (business, civil society, academic).

Whilst the European Parliament has been very active in promoting multistakeholderism, so too have the other salient EU actors involved in Internet governance. The EU's High Level Group on Internet Governance (HLGIG -made up of national representatives responsible for Internet Governance in their respective Member States and chaired by the Commission), for example, has not only been responsible for constructing the EU's position on the continuation of the IGF, but has also, along with the Commission, organised events such as the Hearing on the Future of Internet Governance (May 2009), which brought together European stakeholders to discuss issues such as the WSIS process, Internet security and stability, the role of public authorities, accountability and legitimacy, the internationalisation of Internet governance and the digital divide see http://ec.europa.eu/information_society/policy/internet/). Furthermore, it is evident that the European Commission has, in the words of one official, become 'more comfortable with the concept of multi-stakeholderism' consulting more broadly on 
issues related to the Internet, which has included interaction with civil society as well as key stakeholders (authors' interview, 2010). Finally, leading EU Member States (France, Germany, UK) have established national IGFs in order to discuss Internet related issues and, in the case of the UK, to 'demonstrate that the IGF approach works' (Michael, 2009) - and to build 'on the partnership activity and multistakeholder cooperation that already exists in the UK' (Ibid). .

In summary then, there is no doubt that the institutional form of the IGF (especially multi-stakeholderism) has become a prominent one in the way in which the EU thinks about Internet governance and that in certain policy areas the EU has been influenced by ideas emanating from such discussions to the extent that they have impacted on the way the EU 'does things'. In terms of the IGF's working practices, in the words of one member of the EU HLGIG 'the fact that they are all embracing this model, there is...something to it...I am very confident in saying the IGF is a proven success in the knowledge that there is all this dynamic activity going on...' (author's interview, 2010).

Despite this, however, there is also evidence to suggest that the IGF norm of multistakeholderism, whilst not contested internally, has not been entirely transformative in terms of the practice of the EU. For example, whilst EU actors have been rhetorically supportive of the multi-stakeholder concept, they have not embraced the inclusiveness or indeed transparency involved in the more liberal conceptualisation of it utilised within the global Internet community. In the words of one prominent academic involved in Internet governance, the EU's HLGIG 'should be more transparent and open in the context of multi-stakeholder governance, at least through publishing agendas and inviting non-members to meetings so that it can perhaps find its role in the broader European Internet community' (Hearing on the Future of Internet Governance, May 2009). Others have argued that, in the spirit of multi-stakeholderism, the European Commission should take more of a lead in establishing a European IGF and organizing more local IGFs in order to coordinate European voices on Internet governance and to present a stronger, single voice and message in international fora on Internet governance (Ibid). 


\section{CONCLUSION}

This paper set out to illustrate how the global governance institutions of the Internet have impacted on the EU. In doing this, it is clear that the type of impact has been variable: in one sense, transformative, with the cases of private interest governance and self-regulation within the dot eu regulatory framework and the emergence of a transnational public-private network and the routines and practices that have been established around this with the Eurid Registry at the centre, and the Commission casting the shadow of public hierarchy through defined public policy rules. In another sense, the EU did not simply amplify the self-regulatory or private interest governance norms, but absorbed them within a domestic framework that is was more comfortable and familiar with. It can be argued with the case of dot eu that the Commission (DG IS in particular) was the key policy entrepreneur in this. It is noteworthy that the Commission's legal service, in particular, was only persuaded to accept such global Internet norms if a clear public policy framework for the operational features of dot eu governance was established.

The chapter's focus on the IGF and the EU found the idea of multi-stakeholderism has been absorbed, but adapted to some extent, by almost all EU actors. In this case, 'points of access' in terms for diffusion of multistakeholderism as a norm have been various and locationally multilevel. Here, no significant mass of actors have vetoed such a norm as a basis for Internet governance. In fact, one could argue that in the short life-time of the IGF a relative consensus has grown between key EU actors in Internet governance on the efficacy of the multi-stakeholder concept for finding solutions to many Internet-related issues. Beyond this, it might be argued that the newness of the IGF's modus operandi can also serve to explain in significant part why it has not yet had a transformative impact in the EU, though the case for this will only be established or otherwise through time.

The most interesting dimension to the impact of the IGF on the EU is how it has resulted in dynamic, 'non-linear' effects. Here, direct diffusion to EU Member States with the establishment of national IGFs has occurred. There is also some evidence of indirect, dispersed regional diffusion in the establishment of EuroDIG where the EU is represented. The extent to which the IGF institutional form and its key underlying principles will have a transformational impact, depends on the degree to which key 
actors such as the Commission and the HLGIG become more proactive in engaging with and demonstrating the efficacy of such principles in the practice of Internet governance and policy construction/implementation. It will also depend on if and how multi-stakeholderism, and IGF practices more broadly, lead to clear policy impact and best practice solutions within the broader international Internet governance community. The IGF itself is an institution under review at the time of writing, and there is global contestation relating to its current practices, role and function. EU institutional actors in Internet governance have advocated the continuation of the IGF, and have been influenced by its working practices to the extent that its underlying principles have been absorbed, supported and promoted to some extent. Beyond this, the IGF has also had an influence on policy solutions and best practice within the EU on issues such as IPV6. There is also tentative evidence to suggest that it is likely to continue to do so in the future on issues such as cyber security and child protection, providing innovative solutions to the challenges the EU faces in these areas.

In summary then, the global Internet governance institutions under review in this paper have had significant normative impact on the EU, even though such an impact has been variable because of the dynamics at play. What is clear from this case, however, is that the EU's interaction with ICANN and the IGF has led to a dynamic process of diffusion, where the EU has amplified, or selected and re-interpreted key norms, principles and policy practices. In turn, the EU has thus contributed to the continuation of such norms, principles and practices beyond its borders, whilst in the process asserting its own EU-ised preferences for their evolution in certain cases. 


\section{References}

Christou, George and Seamus Simpson (2007) The New Electronic Marketplace European Governance Strategies in a Globalising Economy, Cheltenham: Edward Elgar.

Christou George and Seamus Simpson (2008) 'Limitations to Transnational Private Governance of the Internet: the dot eu Top Level Domain' in Jean-Christophe Graz and Andreas Nolke (eds.) Transnational Private Governance in the Global Political Economy, London: Routledge, pp. 156-67

Delegation of the European Union to the UN, letter to Ban Ki-moon, 26 March 2010

Doyle, Gillian (2002) Media Ownership, London: Sage.

Dyson, Kenneth and Peter Humphreys (eds) (1986), The Politics of the Communications Revolution in Western Europe, London: Frank Cass.

European Commission (1994), Europe and the Global Information Society; Recommendations to the EC, Brussels: European Commission. (The 'Bangemann Report').

European Commission (2000) 'The Creation of the .eu Internet TLD', Commission Working Paper, 2 February.

European Commission (2004), 'Commission Regulation of 28 April 2004 Laying down Public Policy Rules Concerning the Implementation and Functions of the .eu Top Level Domain and the Principles Governing Registration', EC No 874/2004, OJL162/40, April 30.

European Council of Ministers (1989) 'Council Directive 89/552/EEC of 3 October 1989 on the coordination of certain provisions laid down by Law, Regulation or Administrative Action in Member States concerning the pursuit of television broadcasting activities’ OJ L 298, 17.10.1989, p. 23-30.

European Council of Ministers (1997) 'Directive 97/36/EC of the European Parliament and of the Council of 30 June 1997 amending Council Directive 89/552/EEC on the coordination of certain provisions laid down by law, regulation or administrative action in Member States concerning the pursuit of television broadcasting activities', OJ L 202, 30.7.1997, p. 60-70.

European Parliament (2008) 'Resolution on the Second Internet Governance Forum', B6-0041/2008. Available at:

http://www.europarl.europa.eu/sides/getDoc.do?type=MOTION\&reference=B60080041\&language $=\mathrm{EN}$ (accessed March 2010).

European Parliament and Council (2007) 'Directive 2007/65/EC of the European Parliament and of the Council of 11 December 2007 amending Council Directive 89/552/EEC on the coordination of certain provisions laid 
down by law, regulation or administrative action in Member States concerning the pursuit of television broadcasting activities', Official Journal L 332, 18/12/2007 P. 0027 - 0045.

Goodman, Joseph (2006) Telecommunications Policy-Making in the European Union, Cheltenham: Edward Elgar.

Harcourt, Alison (2005), The European Union and the Regulation of Media Markets, Manchester: MUP.

Hearing on the Future of Internet Governance (2009), Brussels, 6 May 2009. Available as an audio recording at:

http://ec.europa.eu/information_society/policy/internet_gov/index_en.htm (accessed March 2010)

Leib, Volker (2002), 'ICANN - EU can’t: Internet Governance and Europe’s role in the formation of ICANN', Telematics and Informatics, 19, 159-71.

Majone, Giandomenico (2000), 'The Credibility Crisis of Community Regulation', Journal of Common Market Studies, 38 (2), 273-302.

Michael, A. (2009), in Nominet, Messages from Sharm-el-Sheikh, Comments from UK Representatives that attended the Sharm-el-Sheikh Internet Governance Forum, November 2009

Mueller, Milton (2002), Ruling the Root: Internet Governance and the Taming of Cyberspace, Cambridge: MIT Press.

Mueller, M. (2008) 'Governemnts, ICANN and the JPA (part 2)'. Available at: http://blog.internetgovernance.org/blog/_archives/2008/1/29/3494481.html

Radaelli, Claudio (2002) 'The Domestic Impact of European Union Public Policy: Notes on Concepts, Methods and the Challenge of Empirical Research', Politique Europeenne, 5(1), 105-36.

Simpson, Seamus and Rorden Wilkinson (2002), 'Regulatory change and telecommunications governance: a neo-Gramscian analysis', in Peter Humphreys (ed), Special Issue on Telecommunications in Europe, Convergence: The Journal of Research into New Media Technologies, 8 (2), 30-51.

Treaty of Amsterdam (1997) Protocol on Public Service Broadcasting in the EU World Summit on the Information Society (2005), Tunis Agenda for the Information Society, WSIS-05/TUNIS/DOC/6(Rev. 1)-E, 18 November 2005. Available at: http://www.itu.int/wsis/docs2/tunis/off/6rev1.html (accessed March 2010) 